\title{
Red eyes presenting with a fistulous lesion in the left lower extremity: a case report
}

\author{
Natalia Palmou-Fontana ${ }^{1 *}$, Enrique Judez Navarro², Oscar Martín Melero ${ }^{3}$ and Sergio Losa Palacios ${ }^{4}$
}

\begin{abstract}
Introduction: Very few cases of scar sarcoidosis affecting the eyes and bone together have been reported in the last few years.

Case presentation: We report a case of a 49-year-old Spanish man with recurrent bilateral granulomatous uveitis and a fistulous nodular lesion in the left pre-tibial region (scar granuloma) on the site of an 8-year-old scar. He presented with bilateral hilar adenopathies and elevation of inflammatory markers and angiotensin-converting enzyme. A histologically confirmed sarcoid of the tibia with a radiologic appearance unusual for long tubular bone involvement was observed. He also had bilateral ophthalmologic involvement.

Conclusions: Sarcoidosis is a disease of unknown cause histologically characterized by non-caseating granulomas that can involve any organ or tissue. Osseous sarcoidosis is a relatively rare presentation. However, on the basis of cases reported in the literature, sarcoid lesions on bones are generally asymptomatic. Biologic agents are considered an alternative therapy for sarcoidosis resistant to conventional treatment.
\end{abstract}

\section{Introduction}

Scar sarcoidosis of the tibia is considered a rare disease. It is usually described in old scars (10 years) [1], and it is more common in the upper extremities and facial area, together with an exacerbation of sarcoidosis symptoms (Löfgren syndrome) affecting the eyes or, in our patient, bone [2].

In the last few years, very few cases of scar sarcoidosis affecting the eyes or bone have been described in the literature. The appropriate treatment consists of steroids with gradual dose increases until the condition is controlled, followed by immunosuppressive agents such as methotrexate and azathioprine for control of inflammation [3]. Several studies support the use of monoclonal antibodies against tumor necrosis factor $\alpha$, mostly infliximab, in the treatment of pulmonary sarcoidosis, uveitis, cutaneous sarcoidosis including lupus pernio, and neurosarcoidosis [4-12]. Nevertheless, evidence is based on small series or on case reports. We describe a case of a patient with recurrent bilateral granulomatous uveitis together with a fistulous nodular lesion in the left pre-

\footnotetext{
* Correspondence: npalmou@hotmail.com

${ }^{1}$ Rheumatology Department, Hospital General de Almansa, Av de la Circunvalacion s/n, (02640) Almansa, Albacete, Spain

Full list of author information is available at the end of the article
}

tibial region (scar granuloma) on the site of an 8-yearold scar.

\section{Case presentation}

A 49-year-old Spanish man was referred to our hospital by an ophthalmologist in June 2010 with a symptom of red eyes. A uveitis protocol was implemented. A chest X-ray was ordered. The X-ray showed mediastinal adenopathy, for which the patient was referred to the respiratory medicine department. The results of his respiratory function tests were normal, so a high-resolution computed tomographic (CT) scan of the lungs was ordered. As he had no interstitial disease, he was diagnosed with stage I pulmonary sarcoidosis, and no systemic treatment was prescribed. A sacroiliac X-ray and a magnetic resonance imaging scan showed sclerotic changes that appeared chronic. No bone edema was observed. His human leukocyte antigen B27 test was negative, and his angiotensin-converting enzyme (ACE) level was elevated. His physical examination showed that he was hemodynamically stable and afebrile and that his overall health status was good. His musculoskeletal examination revealed a raised fistulous erythematous lesion with serous bloody secretion. He had no erythema or

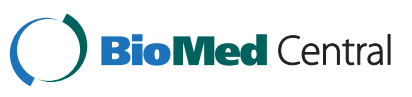


joint effusion. In an examination of his skin, no erythematous bullous lesions were found on his lower extremities.

The patient's blood examination results showed elevated acute-phase reactants (erythrocyte sedimentation rate, C-reactive protein) but no leukocytosis or left shift. His kidney and liver function, electrolytes and clotting were normal. His ACE level was somewhat elevated, and his urine sediment was normal. The results of his serologic tests were negative (hepatitis, HIV, rubella, cytomegalovirus, Epstein-Barr virus, Toxoplasma, Treponema pallidum, Borrelia, Mycoplasma and Chlamydia). To rule out the possibility of tuberculosis, a Mantoux test (negative) and serial urine cultures with auramine staining (negative) were ordered. His highresolution CT scan was compatible with stage I sarcoidosis (bilateral hilar and mediastinal adenopathies).

The patient was also being followed in the internal medicine department for a possible infection after a lesion resembling osteomyelitis was observed on a $\mathrm{CT}$ scan of the left lower limb (Fig. 1). A biopsy was taken, the result of which was compatible with foreign body granuloma. Culture results were negative, and no malignant cells were found, although Pseudomonas and Corynebacterium spp. were isolated in the fistulous secretion. Antibiotics were prescribed for 6 months. With no improvement, the patient was referred to the rheumatology department. A second pre-tibial skin biopsy showed a giant-cell granuloma. Ziehl-Neelsen and periodic acid-Schiff staining results were negative (Fig. 2).

At the same time that the lesion on the patient's left leg worsened, his eye symptoms returned, so he was referred by the ophthalmology department to be assessed for immunosuppressant treatment. Despite improvement with topical and oral corticosteroid therapy, his symptoms persisted.

Treatment was started with prednisone, with the dose being gradually increased from $15 \mathrm{mg} /$ day to $30 \mathrm{mg} /$ day. The patient showed a very good clinical response. He remained afebrile, his malleolar swelling decreased and his fistulous lesion progressively disappeared. Treatment with $15 \mathrm{mg}$ methotrexate was immediately prescribed as a measure to avoid corticosteroid use to a certain extent and to reduce the dose by up to $7.5 \mathrm{mg}$ every 2 weeks. The patient had a successful recovery.

The patient was subsequently followed in the rheumatology, trauma and internal medicine departments, where he was found to be asymptomatic with no further attacks of uveitis. The lesion did not recur.

\section{Discussion}

Sarcoidosis is a multi-systemic granulomatous disease of unknown etiology that particularly affects young people. Its most common symptoms are bilateral hilar adenopathies, pulmonary infiltrates and skin and eye lesions. It is also characterized by the formation of non-caseating granulomas [13-15].

When bone is affected, the patient is normally asymptomatic. The presentation of sarcoidosis is described as lytic and cystic lesions on the fingers and toes (42\%) that do not generally require treatment. However, soft tissues can be affected, with formation of fistulas on the skin that require curettage and corticosteroid therapy or chloroquine, which generally work very well with

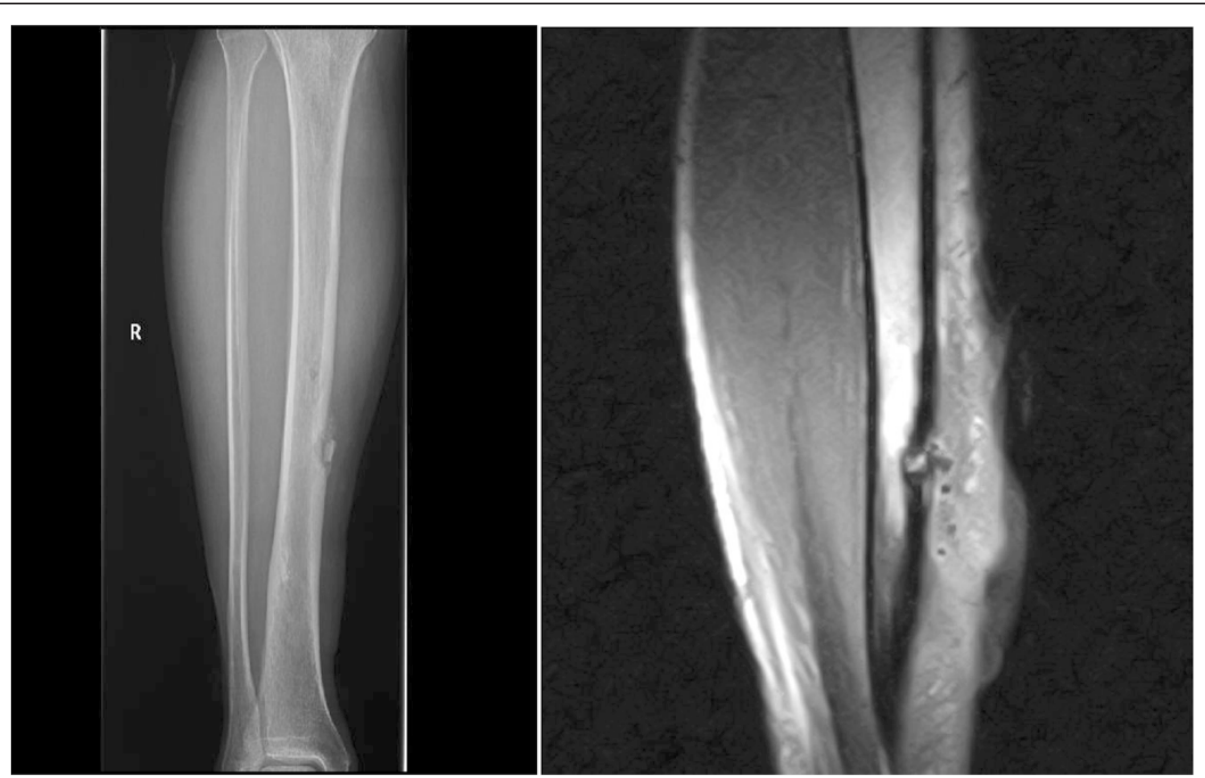

Fig. 1 A lesion resembling osteomyelitis on a computed tomographic scan of the left lower limb 


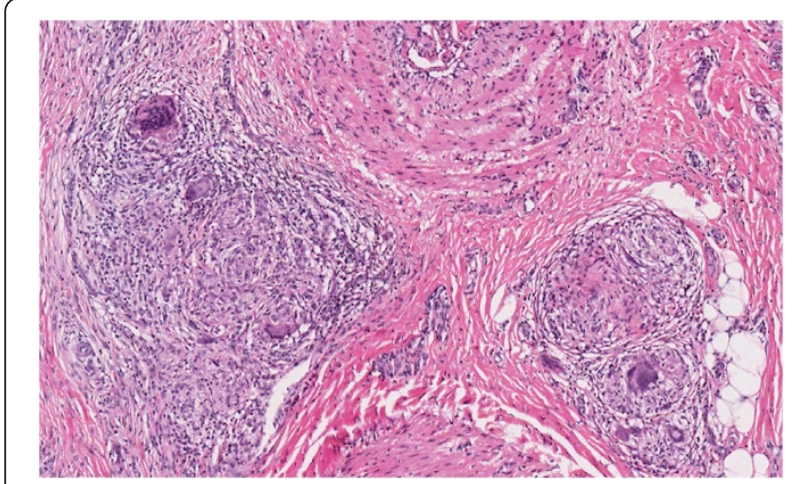

Fig. 2 Epithelioid granuloma with multi-nucleated giant cells without necrosis or acid-fast rod microorganisms (AFB) microorganisms examined using Ziehl-Neelsen and periodic acid-Schiff staining techniques

cutaneous sarcoidosis. The incidence of these lesions is $1-13 \%$, and bone lesions due to sarcoid granulomas are diagnosed by biopsy $[3,13-16]$.

Approximately 38\% of all cases of erythema nodosum are related to sarcoidosis in Löfgren syndrome, and they occur with skin lesions such as plaques, nodules and scars [17-19]. When the eyes are affected, the cases are usually bilateral, recurrent or chronic and secondary and requires ruling out other systemic causes.

In $50-70 \%$ of sarcoidosis cases related to other sites, the eyes are also involved and the eye condition often becomes chronic and recurring [20-22].

ACE values are elevated in $88 \%$ of patients with active sarcoidosis, but using these levels to diagnose the disease can be misleading because approximately $10 \%$ of results are false positives and about $40 \%$ are false negatives. However, measuring the ACE level is useful to monitor disease progression [15].

The cornerstone treatment is based on corticosteroids with gradual dose decreases until the disease is controlled. If the patient's sarcoidosis is still active, immunosuppressive agents followed by second-line treatments such as methotrexate or azathioprine, as well as biologic agents such as infliximab, can be used for several clinical manifestations, although the evidence for these is based on small studies, so more extensive studies are needed to establish use of these treatments [10, 14, 23].

Four other scar sarcoidosis clinical cases have been reported to date. Scar sarcoidosis was found in all of them. This is an uncommon but specific manifestation of sarcoidosis. One of the patients developed scar sarcoidosis on his right finger [24]. Another patient, who had Löfgren syndrome, developed sarcoidosis after a forehead scar [25]. In two cases, sarcoidosis occurred after a herpes zoster scar. One occurred with a disseminated scar that predicted pulmonary involvement [26].

\section{Conclusions}

To the best of our knowledge, this is the first case of tibia sarcoidosis scar reported in the literature. Sarcoidosis generally responds well to corticosteroid therapy, but it is not self-limiting and often also requires the use of an immunosuppressant to avoid corticosteroids and to achieve remission without recurrence. When the eyes are involved, it is often related to other sarcoidosis symptoms. If the disease is not controlled, these symptoms will not be controlled either. Sarcoidosis is usually treated with methotrexate, cyclosporine, azathioprine or cyclophosphamide. New biologic therapies have also been used, with infliximab producing the best response, although the number of studies on the subject is limited $[23,27,28]$.

\section{Consent}

Written informed consent was obtained from the patient for publication of this case report and any accompanying images. A copy of the written consent is available for review by the Editor-in-Chief of this journal.

\section{Abbreviations \\ ACE: angiotensin-converting enzyme; CT: computed tomographic.}

\section{Competing interests}

The authors declare that they have no competing interests.

\section{Authors' contributions}

NPF and EJN participated in the sequence alignment and drafted the manuscript. OMM participated in the sequence alignment and was involved with the ophthalmologic aspects. SLP participated in performing a second pre-tibial skin biopsy. All authors read and approved the final manuscript.

\section{Acknowledgments}

We thank Dr. Miguel Angel Gonzalez-Gay, who contributed to the manuscript by revising the manuscript critically for important intellectual content, but who does not meet the criteria for authorship. Also we thank the pathology department, for providing a picture showing the giant cell granuloma.

\section{Author details}

${ }^{1}$ Rheumatology Department, Hospital General de Almansa, Av de la Circunvalacion s/n, (02640) Almansa, Albacete, Spain. ${ }^{2}$ Rheumatology department, Hospital del Perpetuo Socorro, Albacete, España.

${ }^{3}$ Ophthalmology Department, Hospital General de Albacete, Albacete, España. ${ }^{4}$ Traumatology Department, hospital General de Albacete, Albacete, España.

Received: 9 June 2014 Accepted: 23 July 2015

Published online: 11 September 2015

\section{References}

1. Sorabjee JS, Garje R. Reactivation of old scars: inevitably sarcoid. Postgrad Med J. 2005;81(951):60-1.

2. Selim A, Ehrsam E, Atassi MB, Khachemoune A. Scar sarcoidosis: a case report and brief review. Cutis. 2006;78(6):418-22.

3. Neville E, Carstairs LS, James DG. Bone sarcoidosis. Ann N Y Acad Sci. 1976;278:475-87.

4. Iannuzzi MC, Rybicki BA, Teirstein AS. Sarcoidosis. N Engl J Med. 2007;357(21):2153-65.

5. Lazarus A. Sarcoidosis: epidemiology, etiology, pathogenesis, and genetics. Dis Mon. 2009;55(11):649-60.

6. Holmes J, Lazarus A. Sarcoidosis: extrathoracic manifestations. Dis Mon 2009;55(11):675-92. 
7. Baughman RP, Costabel U, du Bois RM. Treatment of sarcoidosis. Clin Chest Med. 2008;29(3):533-48.

8. Valeyre D, Prasse A, Nunes H, Uzunhan Y, Brillet PY, Müller-Quernheim J. Sarcoidosis. Lancet. 2014;383(9923):1155-67.

9. Cottin V. Update on bioagent therapy in sarcoidosis. F1000 Med Rep. 2010;2:13

10. Judson MA, Baughman RP, Costabel U, Flavin S, Lo KH, Kavuru MS, et al. Efficacy of infliximab in extrapulmonary sarcoidosis: results from a randomised trial. Eur Respir J. 2008;31(6):1189-96.

11. Doty JD, Mazur JE, Judson MA. Treatment of sarcoidosis with infliximab. Chest. 2005;127(3):1064-71.

12. Riancho-Zarrabeitia L, Delgado-Alvarado M, Riancho J, Oterino A, Sedano MJ, Rueda-Gotor J, et al. Anti-TNF-a therapy in the management of severe neurosarcoidosis: a report of five cases from a single centre and literature review. Clin Exp Rheumatol. 2014;32(2):275-84.

13. Nunes $H$, Bouvry D, Soler P, Valeyre D. Sarcoidosis. Orphanet J Rare Dis. 2007;2:46

14. Miliauskas S, Zemaitis M, Sakalauskas R. Sarcoidosis - moving to the new standard of diagnosis? Medicina (Kaunas). 2010;46(7):443-6.

15. Margolis R, Lowder CY. Sarcoidosis. Curr Opin Ophthalmol. 2007;18(6):470-5.

16. James DG, Neville E, Carstairs LS. Bone and joint sarcoidosis. Semin Arthritis Rheum. 1976:6(1):53-81.

17. Cervigón I, Palomo A, Torres LM. [Cutaneous lesions on scars]. Actas Dermosifiliogr. 2007;98(6):433-4. Spanish.

18. Hong YC, Na DJ, Han SH, Lee YD, Cho YS, Han MS. A case of scar sarcoidosis. Korean J Intern Med. 2008;23(4):213-5.

19. Marcoval J, Moreno A, Mañá J. Papular sarcoidosis of the knees: a clue for the diagnosis of erythema nodosum-associated sarcoidosis. J Am Acad Dermatol. 2003;49(1):75-8.

20. Srivastava A, Rajappa M, Kaur J. Uveitis: mechanisms and recent advances in therapy. Clin Chim Acta. 2010;411(17-18):1165-71.

21. Hanno E, Gay D, Boyer S. Two differing presentations of chronic bilateral anterior uveitis. Optometry. 2009:80(2):70-5.

22. Herbort CP, Rao NA, Mochizuki M, members of the Scientific Committee of the First International Workshop on Ocular Sarcoidosis (IWOS). International criteria for the diagnosis of ocular sarcoidosis: results of the first International Workshop on Ocular Sarcoidosis (IWOS). Ocul Immunol Inflamm. 2009;17(3):160-9.

23. Murray PI, Bodaghi B, Sharma OP. Systemic treatment of sarcoidosis. Ocul Immunol Inflamm. 2011;19(2):145-50.

24. Henrichs MP, Streitbürger A, Gosheger G, Surke C, Dierkes C, Hardes J. Scar sarcoidosis on a finger mimicking a rapidly growing soft tissue tumour: a case report. BMC Res Notes. 2012;5:545.

25. Vardhan Reddy Munagala V, Tomar V, Aggarwal A. Reactivation of old scars in an elderly man revealing Löfgren's syndrome. Case Rep Rheumatol. 2013;2013:736143.

26. Su O, Onsun N, Topukçu B, Ozçelik HK, Cakıter AU, Büyükpınarbaşılı N. Disseminated scar sarcoidosis may predict pulmonary involvement in sarcoidosis. Acta Dermatovenerol Alp Pannonica Adriat. 2013;22(3):71-4.

27. Heiligenhaus A, Thurau S, Hennig M, Grajewski RS, Wildner G. Anti-inflammatory treatment of uveitis with biologicals: new treatment options that reflect pathogenetic knowledge of the disease. Graefes Arch Clin Exp Ophthalmol. 2010;248(11):1531-51.

28. Lee FF, Foster CS. Pharmacotherapy of uveitis. Expert Opin Pharmacother. 2010;11(7):1135-46.

\section{Submit your next manuscript to BioMed Central and take full advantage of:}

- Convenient online submission

- Thorough peer review

- No space constraints or color figure charges

- Immediate publication on acceptance

- Inclusion in PubMed, CAS, Scopus and Google Scholar

- Research which is freely available for redistribution

Submit your manuscript at www.biomedcentral.com/submit 